\title{
Kaizen in Practice
}

\author{
Seiji Sugimoto
}

As was discussed in Chap. 2, Kaizen is already popular and widespread throughout the world. This chapter describes, from a technical standpoint, how Kaizen impacts actual work in the workplace. Section 3.1 of this chapter explains the objectives, stakeholders involved in practices, and types of technology, methodology, and tools of Kaizen. Section 3.2 describes detailed features of Kaizen with a focus on technological aspects and implementing structure. Section 3.3 identifies eight guidelines of Kaizen implementation for the consultants and workers who want to introduce Kaizen in the workplace and the management who want to accelerate Kaizen activities. Finally, Section 3.4 discusses the advantages and challenges for introducing and promoting Kaizen, followed by the conclusion. The chapter includes many concrete examples of practice and cases on the ground based on the experiences of the author, which give a clear picture of Kaizen implementation.

\footnotetext{
S. Sugimoto $(\bowtie)$

Consulting Division, Japan Development Service Co., Ltd., Tokyo, Japan e-mail: sugimoto@cba.att.ne.jp 


\subsection{Kaizen as an Integral Part of Technology}

This section illustrates the very broad and comprehensive knowledge and technologies covered under the concept of Kaizen by focusing on its objectives, promoting institutions, and types of technologies and tools in order to draw a complete picture of Kaizen.

\subsubsection{Two Types of Kaizen Based on Objectives}

In factories in the early stage of starting Kaizen activities, good entry points are production processes that workers feel are difficult or unsafe or that create an unstable quality of products. Ideally through Kaizen a factory would develop processes that are easy to operate without safety risks and produce consistently quality products as compared to the state before implementing Kaizen. Gaps between the ideal state and the current state are recognized as problems to be solved through Kaizen (JIS Q 9024 2003). Figure 3.1 shows this comparison between the ideal state and the current state. The complete gray circle on the left side indicates the ideal state and the incomplete circle with a dotted line indicates the current state. The missing part shown by the dotted line in the circle indicates the gap between the ideal state and the current state, which represents problems to be solved by Kaizen.

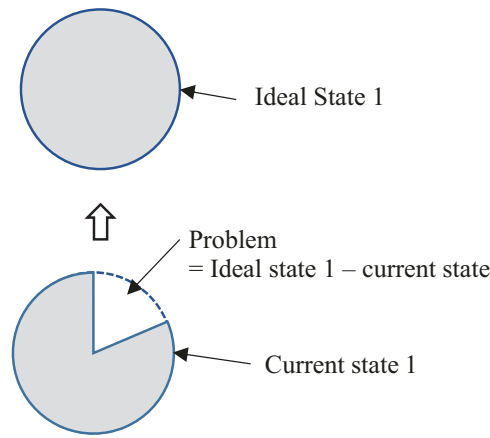

Problem-solving

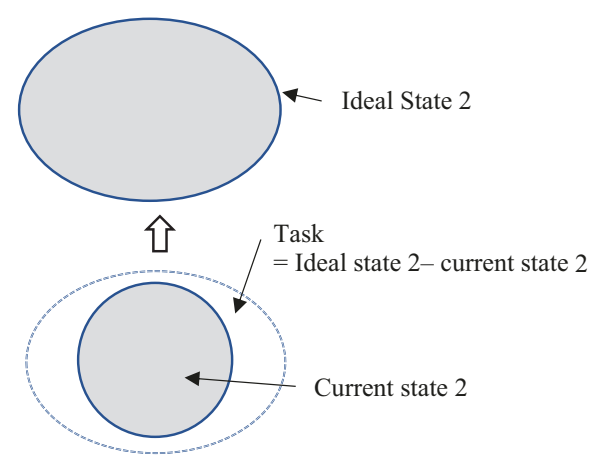

Task-achieving

Fig. 3.1 Two types of Kaizen (problem-solving and task-achieving). (Source: Created by the author) 
A concrete example of a gap between the ideal state and the current state can be illustrated by a case in a T-shirt producing factory. A garment company produces T-shirts following the steps of purchasing the textile, cutting and sewing it to be a T-shirt, and then printing a pattern on it. A finished T-shirt is packed as a complete product. In this factory, the quantity of T-shirts to be produced per person per hour is the performance indicator of the operation. Its target number is $3 \mathrm{~T}$-shirts per person per hour based on the initial design of the factory; this target is the ideal state. However, if the actual production is $2.6 \mathrm{~T}$-shirts per person per hour, the gap between 3 and 2.6-0.4 T-shirt—is the shortfall and the problem to be solved by Kaizen. The left side of Fig. 3.1 shows this ideal state of 3 T-shirts per person per hour as "Ideal state 1," 2.6 T-shirts as "Current state 1," and 0.4 T-shirts as a problem.

There is another type of ideal state that is indicated as "Ideal state 2 " in the right side of Fig. 3.1. Even if the current state is the same as the ideal state 1 , the company may face new competition in their target T-shirt market within a three-year period from imported products made in China or Bangladesh where labor cost is lower and productivity is rapidly improving. If the company recognizes such potential competition in the target market and decides to increase its own productivity by three times within three years, such a target is not a problem, but a task set to realize a managerial strategy. This is shown as "Ideal state 2." This situation is indicated as a gap between the gray circle shown as "Current state 2 " and an oval labeled "Ideal state 2." Such a state is a target of a different dimension, which cannot be achieved through the same procedure of problemsolving (Nitta 1999).

For both ideal states - one from the view of the workplace and the other from management_Kaizen can be defined as activities that fill the gap between the current state and the ideal state by solving problems or achieving tasks on an operational level. In fact, proactive companies that introduce Kaizen while receiving training and consultancy services always keep in mind the ideal state of the company, understand the current state of the company correctly, recognize gaps between the ideal state and the current state, and are willing to fill these gaps. On the other hand, companies without an interest in Kaizen do not possess at least one of the following: "image of the ideal state," "understanding of the current state," "recognition of a gap," or "willingness to fill the gap." 
Table 3.1 Characteristics of two types of Kaizen

\begin{tabular}{|c|c|c|}
\hline & $\begin{array}{l}\text { Problem-solving type of } \\
\text { Kaizen }\end{array}$ & $\begin{array}{l}\text { Task-achieving type of } \\
\text { Kaizen }\end{array}$ \\
\hline Ideal state & $\begin{array}{l}\text { Objective and target } \\
\text { already set }\end{array}$ & $\begin{array}{l}\text { Objective or benchmark } \\
\text { to be achieved in future }\end{array}$ \\
\hline Approach & Bottom-up approach is major & $\begin{array}{l}\text { Top-down approach is } \\
\text { major }\end{array}$ \\
\hline Magnitude of gap & Relatively small gap & Relatively large gap \\
\hline $\begin{array}{l}\text { Focus of Kaizen } \\
\text { activities }\end{array}$ & $\begin{array}{l}\text { Identification of root cause } \\
\text { that creates gap is important }\end{array}$ & $\begin{array}{l}\text { Idea and planning to } \\
\text { fulfill large gap is } \\
\text { important }\end{array}$ \\
\hline $\begin{array}{l}\text { Resources to be } \\
\text { input (labor, } \\
\text { facilities, time, etc.) }\end{array}$ & $\begin{array}{l}\text { Relatively small amount of } \\
\text { input/resource }\end{array}$ & $\begin{array}{l}\text { Relatively large amount } \\
\text { of input/resource }\end{array}$ \\
\hline $\begin{array}{l}\text { Implementer of } \\
\text { Kaizen }\end{array}$ & $\begin{array}{l}\text { Workers in factory, QC circles, } \\
\text { cross-functional team }\end{array}$ & $\begin{array}{l}\text { Management, engineer, } \\
\text { and technician }\end{array}$ \\
\hline
\end{tabular}

Source: Created by the author

Table 3.1 shows key characteristics of the above two types of Kaizen. The prevailing features of the problem-solving type of Kaizen are a bottom-up approach with relatively small inputs, while the task-achieving type of Kaizen is often initiated by a top-down approach with larger inputs of resources.

\subsubsection{Background Information on Kaizen}

This sub-section provides background information related to three issues on Kaizen. The first concerns the relationship between Kaizen and mottainai. Kaizen, which refers to the basic concept of "filling the gap between the ideal state and the current state," can also be understood as a mind-set that wants to remove the feeling of mottainai. ${ }^{1}$ Mottainai is used to refer to situations where things that are still useful are disposed and where inherent capacity or functions are not fully utilized. For example, the feeling of regret at the disposal of offcuts of wood made after cutting parts for the products in a carpenter shop is a sense of mottainai. When you have made only 2.6 T-shirts under the production capacity of $3 \mathrm{~T}$-shirts though

\footnotetext{
${ }^{1}$ Mottainai spread throughout the world thanks to the efforts of Ms. Wangari Maathai (Kenya), who was the first African woman to win the Nobel Peace Prize.
} 
using the same material, labor, and machines, you may feel that the capacity is not fully utilized, a situation that can be called mottainai. Kaizen emerged from the wish to dissolve such a condition of mottainai. Japan, a resource-poor country by nature, was put in a condition of severe scarcity during the period from the defeat in the Second World War in 1945 until recovery of GDP per capita to the level of the pre-war economy in 1955. This is also a period when both the private sector and the government of Japan had enthusiastically introduced technologies from the United States related to quality and productivity improvement. Therefore, it can be said that Kaizen is an effort to realize maximum utilization of available labor, material, and money under conditions that cannot easily be changed.

The second point concerns the relationship between Kaizen and innovation. Because of the modest approach of Kaizen, it is often mistakenly thought that Kaizen does not create innovation, and especially radical innovation. However, Kaizen has been contributing to many incremental innovations in production lines in private companies, through sustaining basic capacity of production as well as promoting continuous improvement. Furthermore, capacities and know-hows developed through Kaizen activities in the workplace often contribute to realization of radical innovation particularly during the stage of trial production of a new product based on an innovative idea.

The third point is about the players working on Kaizen activities. There are two types of stakeholders in the promotion of Kaizen. One are the practitioners of Kaizen including private companies and public institutions who deliver public services such as hospitals, schools, and operators of transport service. The second are promoters of Kaizen such as consultants, trainers, and organizations who support the improvement of the quality and productivity of practitioners. The government and ministries concerned can be promoters of Kaizen based on their policy of and strategy for their own development.

The role of the government as a Kaizen promoter within an industrial development strategy is to strengthen international competitiveness of domestic companies and to promote the development of small and medium-sized enterprises (SMEs) for the sake of job creation (see Chap. 6). The government can also improve service delivery within public sectors. Although private businesses can promote Kaizen in developed countries where the private sector is strong enough, the organizations focused on 
improving productivity operate within the public domain in developing countries. In the case of Ethiopia, the government established Ethiopian Kaizen Institute (EKI), the details of which are described in Chap. 5.

Capacity and the number of capable consultants who can promote Kaizen to practitioners are essential factors for successful Kaizen dissemination. Therefore, the role and form of organization of consultants are explained in the Sections 3.3 and 3.4 of this chapter. On the other hand, there are many experienced large companies who already have built-in capacity for Kaizen activities within their corporate structure, such as Toyota. They can sustain Kaizen activities without external consultants.

\subsubsection{Management Technologies and Inherent Technologies}

The technologies involved in the production of goods can be classified into two types, namely, inherent technologies and management technologies. Inherent technologies mean the knowledge and technologies required to produce goods or services, which can create a physical change in the form or condition of materials, or a chemical change in the character of materials. In contrast, management technologies ${ }^{2}$ mean those required to operate various inherent technologies in combination as a system, to smoothen the interface between humans and machines, and knowledge on motivation, behavior, thought processes, and so on of individuals and groups. Inherent technologies can produce goods, but management technologies including Total Quality Management (TQM), Industrial Engineering (IE), and Total Productive Maintenance (TPM) are essential to produce quality products in a stable manner with high productivity and low cost within a set delivery period.

While inherent technologies are specific to a particular industry, management technologies include many that are applicable to various industries. Quality control is an example (see Fig. 3.2). Thus, there is Kaizen performed by management technologies and Kaizen performed by inherent technologies. One example of the former is the improvement in productivity that results when one worker becomes capable of simultaneously operating two

\footnotetext{
${ }^{2}$ As the term "management technologies" is commonly used by many types of businesses, it should be mastered by Kaizen consultants at both the basic and intermediate levels.
} 
Technologies related to the production of goods

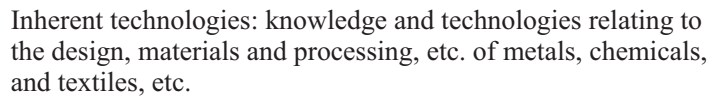

Inherent technologies: knowledge and technologies relating to the design, materials and processing, etc. of metals, chemicals, and textiles, etc.

Management technologies: quality control, industrial engineering,and cost management, etc.

Fig. 3.2 Inherent technologies and management technologies. (Source: Created by the author)

lathes instead of one due to multiple activity analysis, which is a kind of IE tool. In contrast, when the productivity of lathe operation is improved due to an increase in the revolving speed following a change in the material of the bites, this is a type of Kaizen performed by the inherent technology of changing the material of the bites.

While broadly defined Kaizen can involve inherent technologies, Kaizen in the present context is narrowly defined hereafter in this chapter as Kaizen using management technologies for the following reasons:

(A) Management technologies including quality management, quality assurance, and reliability analysis play a major role in the ability to produce a certain quality of products in a constant manner, though inherent technologies play some role.

(B) The application of management systems such as IE (Industrial Engineering) and TPS (Toyota Production System) are indispensable to realize and maintain high productivity.

(C) The utilization of management tools such as VE (Value Engineering), cost planning, and standard cost are essential to create products with cost competitiveness.

(D) Management tools including scheduling, production control, and process management are required to manage and shorten delivery times.

For consultants who provide Kaizen services to various companies, becoming an expert on management technologies tends to have advantages because they are applicable to a wider range of industries than inherent technologies that focus on one specific industry. The combination between management technologies provided by Kaizen consultants and inherent technologies accumulated in the companies often 
broaden the options for Kaizen activities and enhance their effectiveness, especially for quality improvement and TPM.

\subsubsection{Kaizen Systems, Methodologies, and Tools}

Table 3.2 lists examples of Kaizen technologies which are used in the narrowly defined Kaizen. The vertical axis indicates the versatility of technologies and the difficulty of applied use, while the horizontal axis indicates different targets for technology application. Meta-Kaizen technology shown on the bottom includes terms that indicate the overarching procedures of Kaizen implementation through different Kaizen methodologies and tools in different levels.

Of the technologies listed in Table 3.2, those which are important core technologies for Kaizen are briefly explained below. Many of these technologies were developed in the US from the 1910s to the 1930s. They were introduced to Japan around 1950 with the instruction of the US. In the following, names underscored with a wave line are technologies introduced from the US and modified in Japan; names underscored with a straight line are technologies developed in Japan; and the names without an underscore are the technologies of US origin.

\section{TQM (Total Quality Management)}

TQM is a system which combines ideas, tools, mechanisms, and so on designed to maintain and improve quality in general at companies. In the late 1950s, total quality control (TQC) was introduced to Japan with the emphasis that all employees from top management to frontline workers must participate in all departments, ranging from product planning and development, material procurement, marketing, sales, and after-services to personnel affairs and finance, in addition to the manufacturing department in order to produce high-quality products. Based on this idea, TQC combined with broader participation became widely used in Japan in the 1970s. In the US, this Japanized TQC was transformed into a top-down system to make it easier for the intentions of the top management to be thoroughly understood at the production floor. This revised approach was described as TQM. Japan imported this term, and TQC was renamed TQM in 1996. 


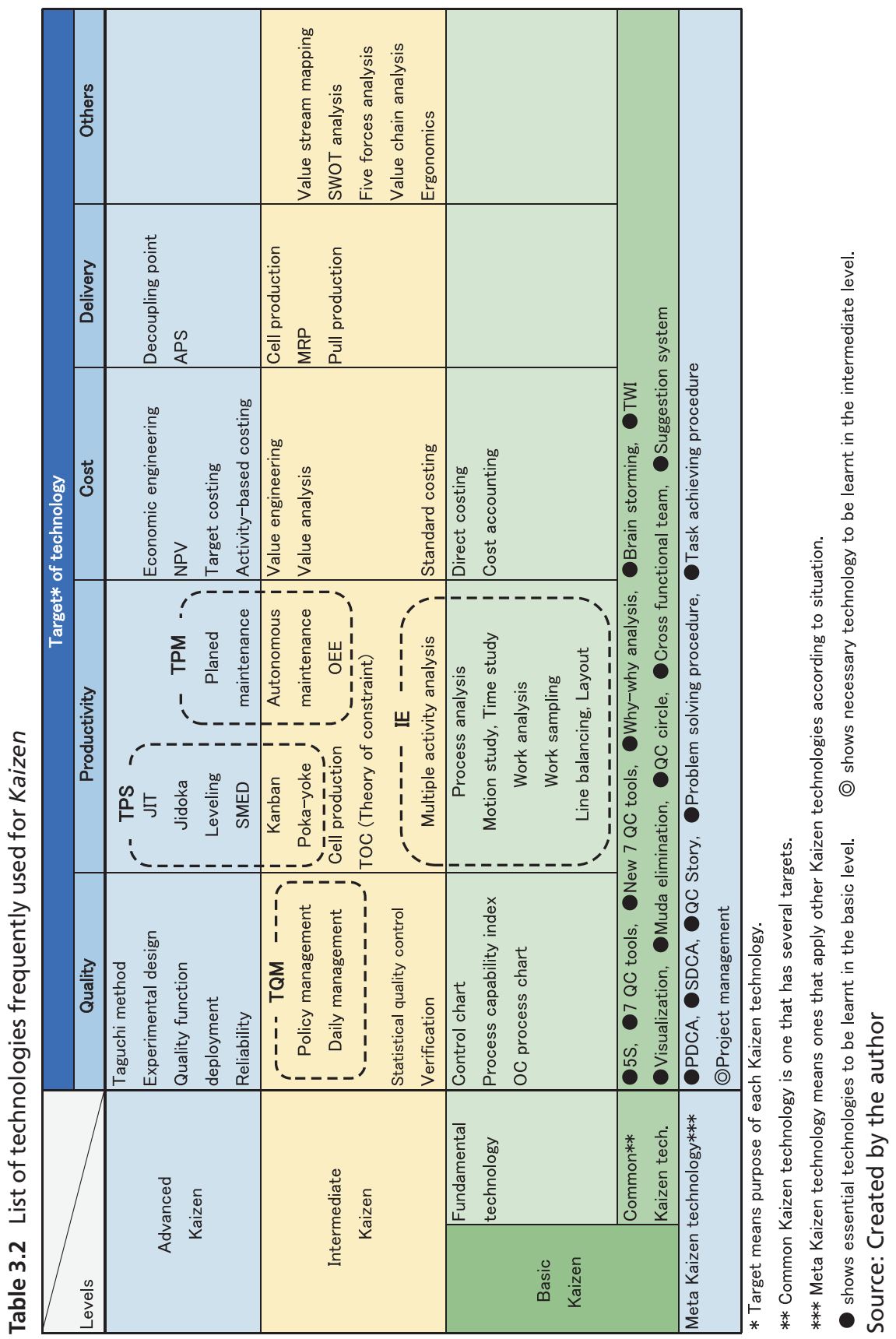


2. TPS (Toyota Production System)

TPS is a production system developed by Toyota through a series of Kaizen efforts based on the philosophy of thoroughly eliminating Muda (waste; see (10) of this sub-section) and pursuing rational manufacturing. TPS is built on two main pillars. One is the idea of "stopping the machine at the moment any abnormality is detected, preventing the production of defective items" (called "jidoka"). The other is the idea of continuing production without stoppage by supplying only the kinds and quantities of items when they are needed for each production process (called "just-in-time") (Ohno 1978). There are not many companies even in Japan which are capable of adopting all pillars of TPS. However, TPS has made a significant impact on many enterprises in Japan as well as in the rest of the world in relation to the concept of Kaizen and how to proceed with Kaizen. The lean production system (or simply Lean) is a generalized production system which is modelled after TPS but renamed for better understanding by Americans (see Chap. 4).

3. Industrial Engineering (IE)

The concept of industrial engineering, introduced by F.W. Taylor and F.B. Gilbreth, was developed as a technology to design, improve, and install a management system whereby people, materials, and equipment act together to perform their functions for the primary purpose of improving productivity (Fujita 1978).

4. TPM (Total Productive Maintenance)

TPM increases productivity through the integrated maintenance of production facilities while aiming at achieving zero work accidents, zero defective products, and zero breakdowns. TPM is characterized by self-maintenance by operators and small group activities with full participation. The idea of the preventive maintenance of machinery arrived at Japan from the US around 1950. The original American idea of maintenance by staff who are exclusively responsible for the maintenance of machinery was Japanized to TPM with the full participation of everyone from the top executive to front-line workers based on the idea that front-line operators are also responsible for the maintenance of machinery by means of conducting preventive maintenance (Suzuki 1992). 
The manual work in production is steadily being replaced by machines and the role played by machinery in production is growing not only in terms of productivity enhancement but also quality, cost, and delivery improvement. This trend is not limited to industrialized countries. In developing countries, there are many cases of the installation of second-hand machines that require careful maintenance. The importance of machinery maintenance in production in developing countries is often greater than in industrialized countries because second-hand machines often operate less reliably, have spare parts that take longer to obtain, and require a long and costly process to call a machine manufacturer's engineer from the country of manufacture for repair when a local agent is unable to repair a broken machine (which occurs fairly often). This is the reason why TPM is such an important Kaizen technology. The following box illustrates how a company in a developing country struggles to maintain machineries of production.

\section{Box 3.1 Defunct Machines Cannibalized for Operating Machines}

A visitor to a factory in a developing country often encounters the scene of a number of obsolete machines being simply stored instead of disposed of. This is a likely situation for the recommendation of the first S (sort) of $5 S$, that is, removal and disposal of unnecessary and non-urgent items from the production floor. However, it is essential to investigate the actual circumstances before making such a recommendation.

As mentioned earlier, many companies in developing countries use second-hand machines, many of which are no longer produced by the original manufacturers with no stock of the relevant spare parts. In this situation, defunct machines kept at a factory are often cannibalized for parts for operating machines. While there is a question of whether or not the storage of such machines resembling scraps to act as a source for spare parts is appropriate, the potential use of defunct machines in this manner should be considered before recommending "sort."

\section{5. $5 \mathrm{~S}$ (Five $S$ )}

The $5 \mathrm{~S}$ stands for sort, set in order, shine, standardize, and sustain. For the purpose of improving the work environment to make it easier to work, unnecessary items in the workplace must be removed (sort), 
places to store necessary items determined with consideration for the ease of returning the items to the designated places after use (set in order), and cleaning regularly conducted (shine). These activities and states of things are normalized (standardize) and are made habitual practices in the workplace (sustain). As the $5 \mathrm{~S}$ primarily reduces wasteful actions of "looking for things" and "transporting something" which do not produce any added value, both productivity and quality improve. Because the involvement of employees in the $5 \mathrm{~S}$ provides the opportunity for them to recognize the value of Kaizen, Kaizen commonly starts with the introduction of the 5S. Many people tend to consider the $5 \mathrm{~S}$ to be merely cleaning of the workplaces as they do not understand the unique definition of each $S$. The reality is that the proper execution of the $5 \mathrm{~S}$ can produce much better effects than commonly anticipated.

6. 7 QC Tools (Seven Quality Control Tools)

The $7 \mathrm{QC}$ tools are a control chart, Pareto chart, cause and effect diagram, check sheet, histogram, stratification, and scatter diagram (Ishihara 1980). These represent the tools used for the present data analysis designed to discover the root causes of a problem using primarily numerical data. They are all old tools except for the cause and effect diagram (fishbone diagram or Ishikawa diagram) invented by Dr. Kaoru Ishikawa of Japan. It is said that the full application of the $7 \mathrm{QC}$ tools can improve (solve) 95\% of problems encountered at the production floor (Ishikawa 1989). New 7 QC tools (relations diagram (association diagram), affinity diagram, tree diagram, matrix diagram, matrix data-analysis diagram, PDPC (process decision program chart), and arrow diagram) that are suitable for analyzing qualitative data have also been developed, while the 7 QC tools are designed to analyze quantitative data.

7. Why-Why Analysis

Why-Why analysis is a tool to logically investigate the cause(s) of a problem by tracing it back to its roots. At Toyota, employees are taught to repeat "why" five times to find or determine the true cause of a problem. The following box shows an application of the analysis. 


\section{Box 3.2 Root Causes Found in Sales Site}

As a concrete case of identifying a root cause by using Why-Why analysis, let me cite my own experience in Argentina. In 2009, five shoemaking factories in Buenos Aires were selected as model factories for the transfer of Kaizen technologies through OJT to counterparts of the government. At that time, Argentina's GDP recorded negative annual growth of $5 \%$ due to the sharp recession that started in the previous year, even though the country had enjoyed nominal economic growth of nearly $10 \%$ a year over the previous four years. The first question I asked on visiting these factories was about the trend in turnover in the previous several years. All five factories were experiencing a downturn with a year-on-year decline of 20-30\% except for one factory which had experienced a $50 \%$ decline in turnover. I found such a decline to be extraordinary and thought that both the factory and those hoping to assist Kaizen would be enthusiastic regarding efforts to improve quality and productivity, which is the standard practice of Kaizen, only after finding the true cause of this massive decline of the turnover, that is, why it occurred. The reason for any abnormality in the market needed to be investigated by regarding the market as a production floor, even though the subject matter falls outside the category of "Kaizen at the workplace." The first step I took was to invite front-line personnel from marketing and sales to get their opinions on quality, design, complaints, range, price, delivery time to shops, sales promotion, and after-sales service, including repair of the shoes made at their factory compared to other shoemakers. The findings of these interviews were that (1) the design and quality which crucially affect the turnover of their shoes were reputedly better than others, (2) the prices tended to be slightly higher than their competitors although they were unlikely to be the cause of twice the large decline in turnover compared to competitors, and (3) the shortcomings were a slightly longer delivery time and insufficient after-sales service.

To identify the cause of the rapid fall in the turnover, an interview survey was arranged with managers and so on of more than 30 leading retail outlets on matters related to shoes manufactured by this factory. Through these interviews, it became clear that the delivery time-almost twice as long as other manufacturer-was incompatible with the expectations of retailers facing the adverse impact of the recession, which necessitated prompt delivery to avoid the loss of sales opportunities due to being out of stock. This long delivery time was the true cause of the business slump at this factory.

Once this discovery had been made, it was time for "Kaizen at the production floor" to show its value. The target of "shortening the delivery 


\section{Box 3.2 (continued)}

time" was introduced and efforts were made to switch from large lot production to small lot production. It took some time to persuade the factory manager to switch the production system as he feared a decline in productivity in the near term due to an increased number of set-up changes associated with small lot production. However, switching to small lot production had a positive impact as the sales growth exceeded that of competitors after three months.

Although this is a somewhat special case of Why-Why analysis, logical investigation of the cause of a problem coupled with verification of the solution through practical application narrowed the scope of the remedial measures to be implemented, resulting in the quick achievement of Kaizen.

\section{TWI (Training Within Industry)}

TWI means the training of subordinates by a team leader or supervisor at a shop where the work is mostly routine. (In other words, it means "job instruction" along with such training themes as "job methods" on how to improve the job, "job relations" on how to handle human relations, and "job safety" on how to conduct work safely.) TWI is a training method which was originally developed in the US and disseminated during the Second World War. In Japan, TWI was disseminated during the post-war period.

9. Visualization

Visualization means the sharing of information on work within an organization, which aims at contributing to the early discovery of problems and the promotion of Kaizen using charts, tables, and graphs. In some cases, sounds or lights are used for the same purpose.

\section{Muda Elimination}

Any activity which does not produce added value is considered to be $M u d a$ (waste). Muda elimination literally means the elimination of over-production $M u d a$, waiting $M u d a$, transport Muda, overprocessing $M u d a$, inventory Muda, motion Muda, and defects Muda (together, they are called the seven Muda) (JMA 1980). For Kaizen, it is important to immediately deal with that Muda which can be easily reduced or eliminated in an early stage of Kaizen implementation. In this chapter, Muda elimination is frequently mentioned as a building block of TPS, in the detailed features of Kaizen, and to 
explain actual cases in the production sites, because it is one of the key entry points to various Kaizen activities.

11. QCC (Quality Control Circle)

QCC is a small group formed at the workplace to improve work at the production floor. Even though the name contains QC, the actual themes for Kaizen are not restricted to quality (JUSE 1980). QCC emerged in 1962 based on the idea of Ishikawa (1989) mentioned in (6), taking its cue from the organizational activities of labor unions. It soon became widespread throughout the world. The participation of a small group(s) consisting of front-line workers in QCC as well as TQM and TPM is a distinctive feature of Kaizen.

12. Cross-Functional Team

A cross-functional team is a team composed of required personnel who are enlisted from a variety of departments or positions to solve a general business challenge faced by the company. By definition, the team deals with problems or tasks that cannot be solved by a single department (JUSE 1980). This team is an important operational unit for TQM.

13. Suggestion System

The suggestion system gives ordinary employees the opportunity to make suggestions regarding desirable improvements relating to their work to the middle or top management. This is an important tool for Kaizen. This system promotes Kaizen while creating a sense of participation in company management among ordinary employees.

14. QC Story (Quality Control Story)

A QC story tells a standardized procedure for problem-solving or task-achieving plus matters related to the presentation of Kaizen results (Nitta 1999). Even though the term QC is used, the actual themes are not restricted to quality.

Although the above section explains management technologies, it must be noted that Kaizen management technologies must be combined with industrial technologies when improvements in the quality of products or the efficiency of equipment is intended. Even for other purposes of Kaizen, knowledge and experience of industrial technologies as well as cost and delivery times of products are useful to promote Kaizen activities. 


\subsection{Fundamental Features of Kaizen}

\subsubsection{TPS as a Symbol of Kaizen}

This section examines the historical impacts of TPS (Toyota Production System) on Japanese-style Kaizen technologies.

The impact of TPS cannot be ignored when discussing Kaizen technologies for productivity enhancement. TPS is a unique production system based on unique ideas and its impact is felt not only in Japan but also in the rest of the world. TPS also offers useful hints for Kaizen for the distribution and service sectors in addition to the manufacturing sector. The uniqueness and originality of TPS are vividly reflected in the following five aspects:

1. To improve profitability, emphasis is placed on cost reduction through the elimination of Muda rather than through a higher product price and/or increased sales volume (Ohno 1978). Toyota currently leads the global automobile market in terms of annual vehicle production along with General Motors (GM) and Volkswagen, but once faced bankruptcy in $1950 .{ }^{3}$ Learning lessons from this crisis, Toyota decided that the rigorous elimination of Muda should be the highest priority to ensure the survival and further development of the company and developed a number of Kaizen tools. This policy resulted in TPS which would later become the foundation for the lean production system.

Throughout the company Toyota lists seven types of Muda, of which over-production $M u d a$ is considered to be the most vicious. The availability of required products at the required quantity and time is sufficient, as Toyota decisively considers any hasty production or production above the required quantity to constitute over-production Muda. Toyota's idea is that it is better to produce the necessary quan-

\footnotetext{
${ }^{3}$ After the Second World War, Japan experienced massive inflation. In 1947, J. M. Dodge, a banker dispatched to Japan by the US military to control inflation and the fiscal deficit, introduced drastic fiscal austerity measures. In the case of the automobile industry, while the sales prices of cars were officially controlled, raw materials and components, such as tires, were excluded from the price control regime. Consequently, automobile manufacturers faced a crisis of survival as their financial deficit increased with the larger output of vehicles. Toyota was no exception (Asahi Shinbun 2013).
} 
tity even if it means a fall of the short-term productivity, negating the common sense associated with the scale merit of mass production. This idea is sustained by the scientific approach of measurement, analysis, and rationalization of the production system. TPS is quite different from Ford's famous production system, which is the sequential mass production of a single product leading to low-cost production and mass sales at a low price, assumed to result in increased profit (Wada 2009).

2. Many companies seek scale merit through the mass production of a single product. However, TPS rejects this idea as it creates Muda associated with over-production. Instead, even if it results in an increase in the number of set-up changes, ${ }^{4}$ TPS aims to reduce the inventory level as well as lead time ${ }^{5}$ through small lot production as much as possible. In the case of the press process, for example, as the work to change a die typically requires two to three hours to complete, there is a tendency to produce many products with the same die, reducing the number of set-up changes. However, this creates intra-lot waiting (lot processing delay) ${ }^{6}$ and intra-process waiting, ${ }^{7}$ extending the time necessary to complete the production (creating a longer delivery time). Because this operation produces more products than immediately required, it creates an in-process inventory, necessitating the allocation of space for its storage and transportation to this space. In the case of TPS, a new method was invented to shorten the die changeover time, as reducing the number of processed products using the same die does not decrease productivity. This method is called the single-minute exchange of die (SMED). SMED has shortened most of the die changeover times to less than ten minutes from the conventional two to three hours (Shingo 1980).

\footnotetext{
${ }^{4} \mathrm{~A}$ set-up change means the setting up of a new operation which is necessary to produce a different product. It includes the replacement of a die, jig, assembly parts and members, and other adjustments until quality is stabilized and pre-manufacturing confirmation of the work contents and cleaning is completed.

${ }^{5}$ Lead time means time required to process raw materials and assembly to produce a product.

${ }^{6}$ Intra-lot waiting means the idle time before and after a process, waiting for full build-up of the unit production volume.

${ }^{7}$ This is the state where an entire lot is waiting for processing work as the processing work involving the lot in question does not proceed.
} 
3. Most companies employ a push production system whereby the amounts of the raw materials to be fed in the first process are determined by the estimated sales volume. In contrast, TPS is a pull production system whereby a production instruction (using a Kanban) is issued from the final process to the upstream processes to ensure that the required volume of products is produced when necessary in correspondence with the actual demand. In reality, a production instruction is also issued in a push production system not only to the first process but also to all other processes. Once a problem occurs at an intermediate process, the actual state of production begins to differ from the issued production instruction. In the case of the pull production system, the production instruction issued from a downstream process to its previous process can absorb a small fluctuation in the production volume, minimizing any adjustment between the plan and actual performance (Monden 1985). In other words, the production system of making to stock tries to "sell what is produced," while TPS tries to "make what is sold."

4. Most factories hold some stock (of raw materials, work in process, completed products, etc.) to avoid adverse impacts on immediate production and sales of an unanticipated situation, such as equipment breakdown, non-supply of raw materials, sudden time off by workers, occurrence of defective products above an assumed level, and so on. In TPS, the stock level is reduced to the lowest possible level to make any problem on the production floor visible, so that problems can be quickly rectified as measures designed to prevent the re-occurrence of the same problems are introduced. In other words, the former absorbs problems with stock, which may conceal the seriousness of such problems, while TPS tries to quickly find the occurrence of problems in order to take suitable steps to solve them quickly and prevent any further occurrence (JMA 1980).

5. In the case of continuous production involving a conveyor belt, the entire operation is divided into a series of simple tasks, each of which can be conducted by a single skilled worker. Such simple tasks, however, promote a feeling of boredom, often resulting in a decline of morale. With TPS, workers are encouraged to develop multiple skills. Moreover, the provision of opportunities to present thoughts and ideas 
through participation in production floor small group activities and the proposal system leads to the capacity building of ordinary employees.

Companies positioned opposite to TPS described above are typically those that employ Ford's production system, ${ }^{8}$ a mass production system relying on the interchangeability of parts and an assembly line using a conveyor belt. The system was developed over a period of five years from its initial conception to realization in the US, was established around 1910, and is still used by many factories around the world. In contrast, TPS is a production system resulting from thorough thinking by Toyota to obtain cost competitiveness in a high-mix low-volume production system. TPS was designed to enable the company's survival in the small post-war automobile market in Japan. The system was established as the result of Kaizen efforts over a period of some 20 years and its introduction to all Toyota plants was completed in 1962 (Wada 2009).

Although TPS has had a great impact on the philosophy and methods of Kaizen, it has become somewhat tacit knowledge because of the few systematic guidelines applicable to various types of companies unlike International Organization for Standardization (ISO) standards and also because of the use of many unique terms. The lean production system can be described as a system which has restructured the tacit knowledge associated with TPS and converted it to explicit knowledge so that it can be easily understood by non-Japanese companies. As such, it is an example of the globalization of TPS (see Chap. 4 for comparison between TPS and Lean).

\subsubsection{Detailed Features of Kaizen}

The following four matters describe general features of Kaizen:

(i) Pursues cost reduction through the rigorous elimination of Muda;

(ii) Aims to enhance the sense of participation in Kaizen, morale, and capabilities of front-line workers;

\footnotetext{
${ }^{8}$ Toyota production system and Ford production system can be compared with production based on order vs make-to-stock, pull production vs push production, pursuit of profit by small lot production vs pursuit of profit by large lot production, and so on.
} 
(iii) Proceeds gradually from basic Kaizen to advanced Kaizen in correspondence with the capacity of the company or organization;

(iv) Gives priority to Kaizen relying on analytic thinking rather than large investment.

\subsubsection{Cost Reduction Through the Rigorous Elimination of Muda}

As described in the previous sub-section, Kaizen is strongly influenced by the philosophy of Toyota which is one of the most representative giant companies of Japan. The idea is to remove any negative aspects (Muda) to increase the profit. Though a company undertakes the sales promotion of its products against the products of its competitors, the product price and sales volume are largely determined by the market and cannot be totally controlled simply by internal efforts. In contrast, the elimination of Muda can be achieved solely by internal efforts and, therefore, can easily be a target for Kaizen.

\subsubsection{Sense of Participation and Capacity Building Among Front-Line Workers}

Kaizen aims at not only improving quality and productivity but also at enhancing the morale of workers along with their capacity. Kaizen is driven not by investment in Kaizen technologies or mechanical equipment but by investment in front-line workers, supervisors, and managers. The capacity building of these people through Kaizen activities makes it possible for them to tackle advanced Kaizen themes, progressing from simpler Kaizen in the beginning. When viewed from this angle, the production floor of Toyota can be described as "a learning organization." As will be mentioned later, one of the leading features of Kaizen is its emphasis on workers' logical thinking and empirical knowledge rather than money. Kaizen cannot simply be achieved with the application of Kaizen technologies. In addition to such technologies, interest in Kaizen among all stakeholders and a sense of participation and the capacity building of workers are essential. The positive effects of Kaizen only emerge and continue when the technological and human aspects are engaged with each other like a pair of wheels. 


\subsubsection{Gradual Application of Kaizen at Different Levels}

As listed in Section 3.1.4, Kaizen includes a variety of systems, methodologies, and tools. They can be classified according to their level of applicability as basic, intermediate, or advanced Kaizen as indicated in Table 3.2. In the basic Kaizen, $5 \mathrm{~S}$ is a typical first method to be introduced. That is because $5 \mathrm{~S}$ (or at least $2 \mathrm{~S}$, sort and set in order) is an empirical prerequisite for balance improvements of production lines and reductions in the rejection rate. In addition, $5 \mathrm{~S}$ can create tangible changes in the workplace, through which workers can recognize the benefits of Kaizen and be more supportive to it. After achieving a better work environment and stimulating the Kaizen mind of the workers, Muda elimination is the next step. Although Muda elimination includes practices at different levels from easy to difficult, the easiest one in terms of designing and implementation can be selected as the first step, which can foster further self-confidence in workers toward higher levels of Kaizen. When a small and medium-sized enterprise (SME) tries to introduce a comprehensive Kaizen technology system under Western ways of application such as Lean, Six Sigma, or ISO, it is often recommended to introduce the entire system at once. Since with Kaizen there is a way to start with an easy step, such as the 5S, Kaizen is easier to adopt by SMEs with a lower ability to apply Kaizen technologies. Metaphorically speaking, Six Sigma and ISO can be described as restaurants offering a full-course menu, while Kaizen is a restaurant offering an a la carte menu as well. It goes without saying which restaurant is easier to visit for a customer with limited digestive capacity as well as funds.

\subsubsection{Relying on Analytic Thinking Rather Than Large Investment}

Here is a useful example in Argentina. An old factory building which became cramped was replaced by a new larger factory, which the owner asked me to diagnose. The new factory was found to be more modern in appearance, but the job flow set by the shop-based machine layout where machines of the same type are positioned together remained the same. 
One clear difference was that the distance between the machines in the new factory was much farther than before with an increased number of products in process being piled up around each machine. This view made the author instantly suspect that investment increased Muda. A relaxed machine layout lengthens the moving distance of goods, while an increased number of products in process not only lengthens the lead time but also increases the handling workload relating to work in process. Any investment not accompanied by the viewpoint of Kaizen can actually damage the quality and/or productivity in many cases. The example shown in the following box, which argues that relocation to a larger factory is made unnecessary due to Kaizen of the layout, comes from Ethiopia.

\section{Box 3.3 Capacity Expansion Through a Change of the Layout}

The owner of a feed factory which has a long rectangular shape of $6 \mathrm{~m}$ wide and $20 \mathrm{~m}$ deep wanted to relocate to a new larger factory in several months' time as the existing factory had become cramped due to increased production. The main machines, that is, crusher and mixer, are positioned at the far end of the factory building with an operating rate of $50 \%$. The factory has one aisle almost at the center of the floor which runs from the entrance to the far end. Maize and other raw materials for mixed feed are placed on both sides of this aisle. With this kind of layout, raw materials are temporarily placed in designated areas and ultimately transported to the area of the machinery. Processed and mixed products are moved to the product yard near the entrance for subsequent loading onto trucks. Some 20 workers work at the factory, $70 \%$ of whom are engaged in the in-factory transportation, loading and unloading the raw materials and products from trucks (see Fig. 3.3).

All of the raw materials ultimately require transportation to the far end and completed products must be transported from the far end to the entrance. This is a layout whereby the lines of flow of goods and people have been made the longest. Under the instructions of the author, the machines are relocated near the entrance, while raw materials with a heavy weight in the final product (maize, etc.) are now stocked near the entrance. Those with a lighter weight in the final product (various minerals, vitamins, etc.) are stocked toward the far end. The work to change the layout was conducted over a weekend (Saturday and Sunday). On Monday, the productivity increased by $37 \%$ without any special instructions on how to conduct the work and the day's work was completed three hours before the factory's closing time. The workers responsible for transportation are 


\section{Box 3.3 (continued)}
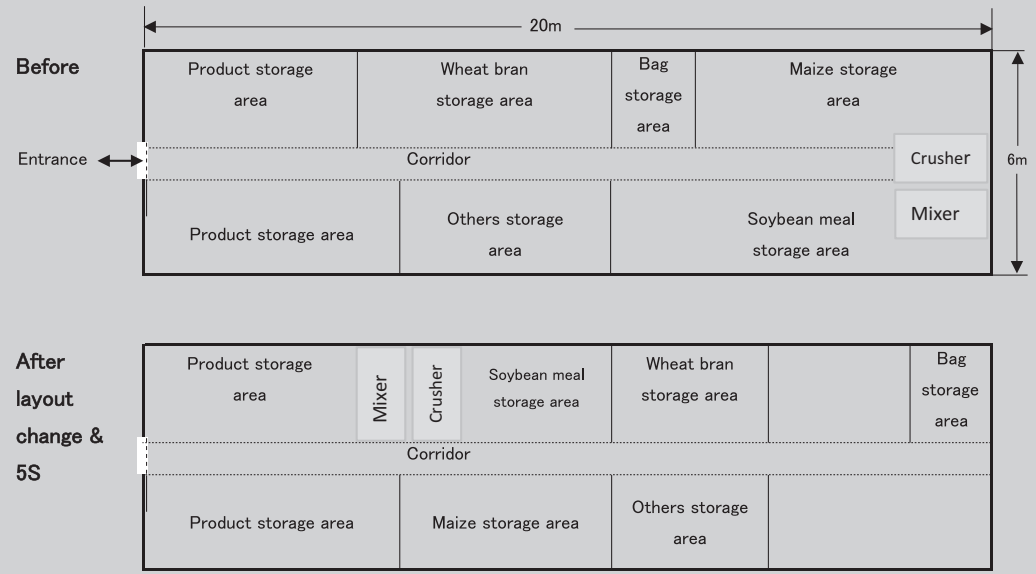

Fig. 3.3 Example of layout change in the factory. (Source: Created by the author)

said to be jubilant as their work is now less physically demanding. Trial calculation shows that no additional workers are required even if the production volume increases by $60 \%$, meaning that the existing factory can cope with such level of production.

The example described in the box is a real case where the relocation of a factory and the recruitment of new workers, both of which can be considered strategic issues for business management, became unnecessary for several years due to the basic Kaizen which improved the factory layout. In this case, it is also possible to introduce a conveyor belt for in-factory transportation to replace manual labor by a mechanical means. However, the introduction of a conveyor belt without changing the layout constitutes the "mechanization of Muda," causing double Muda.

\footnotetext{
${ }^{9}$ If the current flow line (travelling route of people and goods) of $40 \mathrm{~m}$ can be shortened to $10 \mathrm{~m}$ by a change of the layout, a flow line of $30 \mathrm{~m}$ constitutes $M u d a$. Investment in a conveyor belt for the transportation of goods while leaving a long line of flow means investment in the mechanization of a $30 \mathrm{~m}$ long wasteful line of flow. The author calls this the "mechanization of Muda" or "investment in Muda."
} 
Large investment is required for such large changes as the construction of a new factory and the introduction of high-capacity machinery or the introduction of IoT (Internet of Things). If successful, this investment results in a substantial increase in the production capacity. If it fails, however, it may lead to a situation where the company's survival is threatened. In contrast, one attempt at Kaizen has a limited effect, but continuous Kaizen efforts can lead to a major achievement. As described earlier, Toyota spent 20 years practicing Kaizen to finally establish TPS, an innovative production system.

\subsection{Guidelines of Kaizen Implementation}

This section explains eight guidelines for implementing Kaizen to be noted when a company or organization introduces Kaizen. Of these, four are for consultants and workers, while the remaining four are for Kaizen management.

\subsubsection{Four Guidelines for Consultants and Workers}

1. Immediate action is the first priority, followed by continuous Kaizen.

Unlike administrative reform, Kaizen assumes the accumulation of small changes. Because of this, the cost is small, and any unsuccessful outcome does not cause much damage to the company. Kaizen can be implemented even when a new system for its implementation is not fully in place. It is sufficient to start wherever it can be started.

Let us consider work in which a machine operator checks any loosening of the bolts as part of self-maintenance for the purpose of retightening if loosened bolts are found. When the machine to be inspected uses the type of bolt shown in Fig. 3.4, daily checking using a spanner in many places is time-consuming. The drawing of a narrow line which runs continually from the bolt, nut, and base as shown here makes it easier to detect any loosening as a misaligned line means a loosening of 


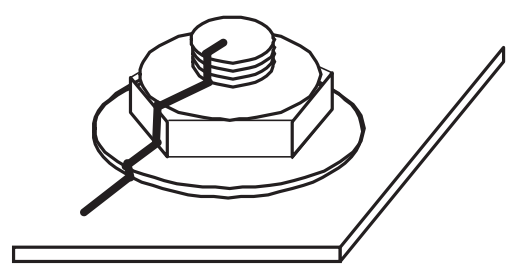

Fig. 3.4 Loosened bolt instantly made visible with simple Kaizen. (Source: Created by the author)

the bolt. The simple act of drawing a line constitutes an act of Kaizen when implemented.

An immediate action is very important for Kaizen, and it is not necessary to be afraid of failure when attempting Kaizen. Failure should be treated as an experience to be referred to for new attempts that take a different approach. In Japan, there is a company which awards prizes to the QC circles experiencing a major Kaizen failure for the purpose of encouraging the implementation of Kaizen in the first place.

2. On-the-spot observation is more important than deskbound discussions.

In some countries, highly educated engineers with professional knowledge may not like the idea of visiting the field as they dislike getting dirty with machine oil. They discuss the causes of problems in the conference room based on advanced professional knowledge learned at university or graduate school. For example, they list as many possible causes of a problem that they can think of during a brainstorming session and compile these causes in the form of a cause and effect diagram. The causes indicated on such a diagram, however, are simply possible causes. In general, the number of real root causes of a problem is one or slightly more. Cases are observed where efforts are made to come up with measures for all possible causes without narrowing down the likely root causes. The implementation of all measures requires massive human resources as well as funding in addition to the length of time needed to find the real root cause(s). As such, this approach is unproductive. Failure to narrow down the root causes can be attributed to insufficient on-the-spot observation in most cases. 
While the logical pursuit of the root cause using Why-Why analysis is helpful, the validity of the finally identified cause must be verified in the field. In the case of Kaizen at the production floor, the root cause of a problem is assumed to lie at the production floor and clues for a solution are often expected to be found at the same production floor, as the example in the following box portrays.

\section{Box 3.4 The Cause of Defective Product and Tips of Kaizen Detected on the Sites}

This is a case of a factory that produces canvas shoes in Argentina. In response to a request from the factory management who wanted to reduce the rate of defective products, the author and trainees who would be Kaizen consultants in the counterpart organization of Japan International Cooperation Agency (JICA) project started consulting on quality improvements in collaboration with the Quality Control (QC) staff of the factory. First, based on the theory of QC, we counted defect rates in accordance with type of shoes, side (left or right) of pairs, and six parts of each shoe and then drew a Pareto chart. The result showed that the most common defect, about half of all defects, was mal-adhesion between a particular part of shoe soles and the canvas. The next step as a common method was to prepare a fishbone diagram that indicated possible causes of defects identified through a brainstorming session. However, such practices may not bring productive results if the site observation is not conducted carefully enough. Therefore, the author requested the trainees and QC staff to carefully observe the production floors in the factory before the brainstorming session. Through this process, we found that some of gluing work of shoe parts was outsourced. Hence we divided the sample data of defects to the shoes with the outsourced process and without the process, reanalyzed the defect rates, finding that the outsourced products showed significantly high rate of defects. Before discussing the reason why the products with the outsourced process had a high defect rate, what we needed was site observation. The author, trainees, and QC staff visited the company to which the factory outsourced the gluing process and then understood the reasons for high defects immediately following the inspection of its work process. There are two reasons: one is the use of low-quality glue at a cheap price, and another is the lack of a process to bleed air contained in the adhesive face by tapping on the glued parts after adhesion. Countermeasures derived from these observations were immediately introduced, which halved the defect rate. This case demonstrates that as the reasons for defects exist in the workplace, so too do the hints for countermeasures. 


\section{Quality oriented by consumer prioritize}

There is one principle which should never be forgotten when implementing Kaizen. This principle demands that Kaizen provide greater customer satisfaction. Kaizen which damages customer satisfaction is not Kaizen but a change for the worse. Here is an example: a manufacturer may change the required period for delivery of own its products to customers, from 7 days to 15 days, in order to improve their delivery rate within the set period. This change is not Kaizen if the manufacture does not consider the convenience of customers. The idea of being customer-oriented may not come naturally on the production floor as front-line workers have hardly any opportunity to have direct contact with customers. In this case, the post-process of production in the factory is like a "customer" because the previous process works as supplier to the next process as buyer. Customer satisfaction should be understood as the ease of work in the post-process, as this line of thinking from one process to the next eventually leads to the real customers who are the users (Hosoya 1984).

Customer satisfaction can be expressed by the value or cost which customers consider appropriate for a product or service that they receive. There could be a change, such as lowering the function or capability of a product or the withdrawal of polite service which may appear to lower the satisfaction of customers at first glance. However, if the price of the products drops more than the lowered customer satisfaction (or any cost increase due to a change can be compensated with other benefits for the customer), this change can be described as an act of Kaizen. One example is that of a dry cleaner extending the delivery time from three days to five days while reducing the price by half. In this case, it is essential to carefully determine the reaction of customers to this change. Lowering the product or service value based on prejudice on the part of the seller involves considerable risk.

The quality-first policy means, in fact, the same as the customeroriented policy even though the phrases used are different. Quality in this case means broadly defined quality which comprehensively covers not only the product quality but also the quality of marketing, after-service and other auxiliary services, and price. 


\section{Focus on bottleneck}

Consider the case shown in Fig. 3.5 that illustrates a production line composed of three processes, that is, cutting, boring, and polishing. The processing time to complete a product is one minute for cutting, three minutes for boring, and two minutes for polishing. The production capacity of this production line is determined by the processing time for boring. To be more precise, 20 products can be produced in 1 hour (60 minutes $\div 3$ minutes). When only the cutting process is looked at, the production capacity is 60 products per hour. Similarly, the production capacity is 30 products per hour for the polishing process. When each process is operated to its full capacity, there is a build-up of 40 products in the process per hour between the cutting process and boring process. Meanwhile, the polishing process incurs idle time of $20 \mathrm{~min}$ utes per hour because of the non-forwarding of work in process from the boring process.

It is evident that the boring process constitutes a bottleneck for this production line as the process with the lowest processing capacity determines the production capacity of the production line. If the processing time of the boring process can be shortened from three minutes to two

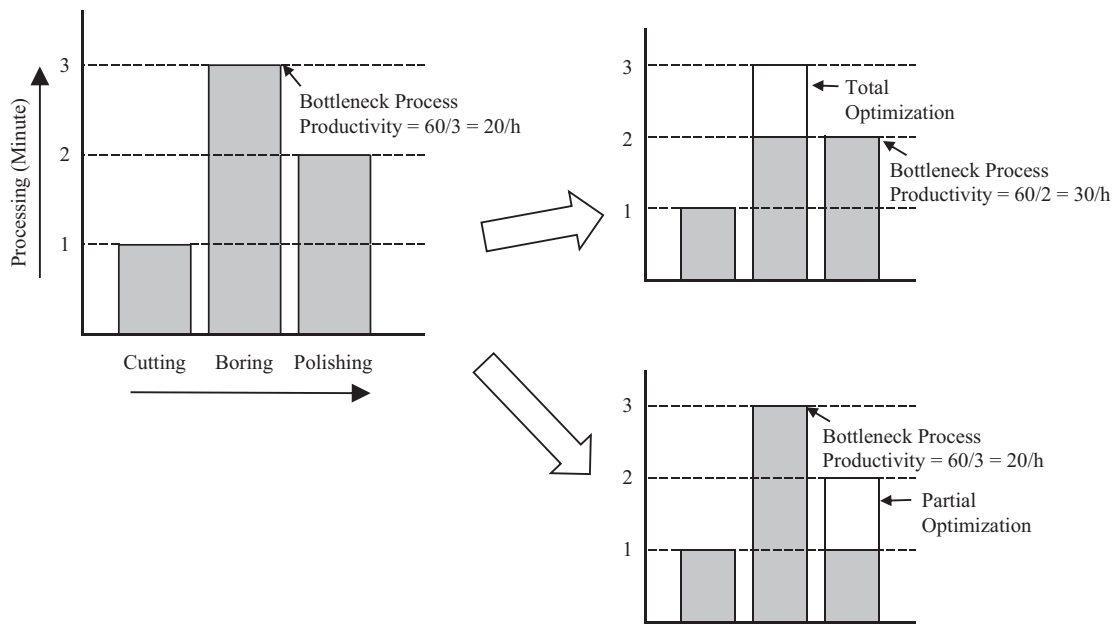

Fig. 3.5 Total optimization and partial optimization. (Source: Created by the author) 
minutes, the capacity of the production line will improve by $50 \%$ without any Kaizen directed toward the other two processes. In contrast, shortening the processing time of the polishing process by $50 \%$ will not change the capacity of the production line. In this particular case, Kaizen for the cutting or polishing processes is partial optimization as such Kaizen does not lead to Kaizen of the whole process. However, Kaizen of the boring process is almost total optimization to improve the productivity of the production line even though it is only Kaizen for one process. To ensure that Kaizen leads to improvement of the company performance, Kaizen should focus on the bottleneck work, process, or department. If Kaizen for partial optimization is found to be helpful for the vitalization and/or capacity development of the workplace, this type of Kaizen should receive the first priority. Similarly, the viewpoint of a bottleneck is quite useful for Kaizen for the product quality. What is important for Kaizen for the product or service quality is to begin with the most serious quality-related problem.

\subsubsection{Four Guidelines for Kaizen Management}

5. Strong commitment by the owner is essential for successful Kaizen.

Compared to the Six Sigma and so on, Kaizen is believed to be a bottom-up approach, making the best use of the own initiative of front-line workers. This understanding is partly but not completely correct. Let us assume a situation where Kaizen activities start in each department following a kick-off meeting at which the owner expresses his expectations for Kaizen. If the owner subsequently adopts a stance of waiting for positive results to emerge on the grounds that "Kaizen is a bottom-up activity," his expectations will not be met. It must be pointed out that leadership is responsible for the (1) presentation of a vision to be pursued by all employees, (2) promotion of motivation, and (3) achievement of the task. In this context, commitment is a concept congruent with the (2) promotion of motivation. To be more precise, it is essential for the owner to show to the employees constant interests in as well as commitment to Kaizen by means of listening to production floor workers about their progress, encouraging 
their efforts, and, in some cases, making decisions to solve important problems on the production floor. It is also essential for the top executive to personally attend meetings where Kaizen achievements are reported, to comment on reports, and to encourage further efforts. This is because there is a strong link between the strength of the commitment of the owner to Kaizen and the actual scale of Kaizen achievement.

6. Kaizen is for both change at the production floor and human resources development.

Kaizen follows a bottom-up approach combined with a gentle topdown approach. However, if Kaizen is based on impulse, it is neither very effective nor efficient. Kaizen often follows the steps listed below after it has become a familiar practice on the production floor. Those in bold are particularly important activities.

(a) Kaizen kick-off

(b) Implementation of the $5 \mathrm{~S}$

(c) Formulation of a body (i.e., QCC or cross-functional team) to implement Kaizen

(d) Training on the basic concept and proceedings of Kaizen

(e) Establishment of a suggestion system

(f) Kaizen of Muda where problems appear easy to solve

(g) Improvement of the work

(h) Change in the layout

(i) Elimination of seven Muda

Out of the above nine steps, (a), (c), and (d) are steps focusing on mind-set change and readiness of the workers. The implementation of $5 \mathrm{~S}$ in step (b) also promotes a Kaizen mind-set as described in (iii) of 3.2.2. Step (c) is the formulation of an implementing body of Kaizen that can provide opportunities for mutual stimulation and learning among coworkers, which is an essential process of human development. At step (d), workers can learn the basic concept and proceedings that capture the meaning of Kaizen, aims, basic ways of thinking, and methodologies. Step (e) also has the effect of sustaining workers' understanding that the current state can be improved as well as their efforts to find a trigger for 
improvement. Even in steps (g), (h), and (i), momentum and knowledge on Kaizen can be shared among departments of the company if a session on Kaizen experience sharing is organized periodically. In these ways, Kaizen is a process carried out by a pair of wheels of Kaizen focusing on material (quality, productivity, cost, and delivery) and people.

Kōnosuke Matsushita, the founder of Panasonic, a world-famous Japanese manufacturer of household electrical appliances (Matsushita 2006), made a well-known remark, "Our company is where we develop people. We also make electrical appliances." His statement clearly indicates a corporate objective which places human resources development and product manufacturing on the same level. The book Fundamentals of QC Circle (JUSE 1980), referred to as the bible for QC circle activities, lists on its opening page the three basic principles of QC circle activities, as shown in Fig. 3.6. QC circle activities aim at encouraging selfdevelopment and mutual development to improve the capacity of all circle members (corresponding to No. 1 on the list) by means of independently solving workplace problems related to products and jobs through group activities (No. 3 on the list), thereby creating a pleasant and vital workplace (No. 2 on the list).

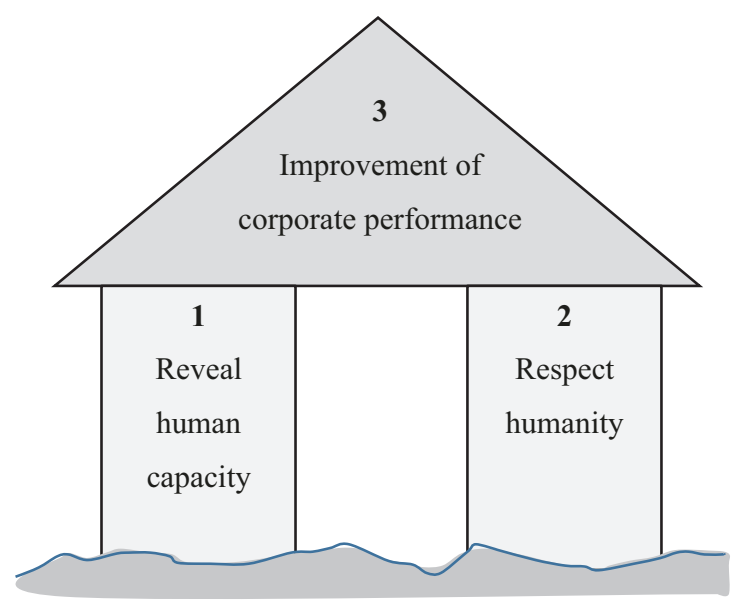

Fig. 3.6 Basic principles of QC circle activities. (Source: Created by the author based on "Fundamentals of QC Circle (1980)," JUSE Press, Ltd.) 
7. Once surplus manpower is generated through labor-saving by Kaizen, excellent employees should be picked out and assigned to prepare for the launch of a new product and to pursue further Kaizen

Kaizen of productivity generates surplus manpower on the production floor. This situation leads to the question of who should be removed. There are typically two options to deal with this situation. One is to make the surplus workers redundant for their inferior work-related competence. This is probably the worst option as the remaining workers are unlikely to further cooperate with Kaizen. This option must be avoided at all costs. A better way of labor-saving is to pick out excellent workers from the production floor and to assign them to more creative jobs, such as leaders of Kaizen on the production floor and leaders of the launch of a new product. Such assignments make the picked workers realize that they have been assessed as excellent workers, while the morale of other front-line workers is not adversely affected.

\section{Motivation to implement Kaizen}

Sustaining interest in Kaizen is essential to ensure the continuity and ultimate success of Kaizen. What is important to sustain this interest is the motivation of those implementing Kaizen. According to the psychology of learning, motivation has three levels, ranging from economic motivation at the lowest level to affiliation and achievement motivation at the highest level (Ichikawa 1995). Affiliation motivation is a type of motivation which originates from good human relationships in the workplace and achievement motivation is a type of motivation which upholds a relatively high objective, and which tries to overcome obstacles to achieve the objective. Once motivation of a lower level is satisfied, motivation at the next level becomes stronger. Small group activities often used for Kaizen play an important role in satisfying affiliation and achievement motivation, but they may not be effective enough to continue Kaizen. In developing countries, it is fairly common for economic motivation to be far stronger than anticipated. ${ }^{10}$

\footnotetext{
${ }^{10}$ A public servant who has become a Kaizen consultant appears to have strong achievement motivation and intrinsic motivation, but many are seeking the opportunity to change their jobs because
} 
Motivation is further divided into extrinsic and intrinsic motivations. The former is the result of stimulation by means of evaluation, reward, punishment, or imposition by someone other than the person concerned. In contrast, intrinsic motivation is the result of one's own inner interest, attention, and/or drive. Intrinsic motivation is believed to be favorable from the viewpoint of perpetuity or personal growth, but extrinsic motivation has a very strong impact in developing countries.

A system to distribute the effects of Kaizen has profound effect in developing countries. This system is related with extrinsic motivation working on economic motivation. One example is as follows:

1. The target of Kaizen, for example, is to decrease the amount of defective products by half, which may bring additional income estimated as $(\$ 20,000)$.

2. If the abovementioned target was completed, profit derived by Kaizen would be allocated to employees at a predetermined rate, for example, $60 \%$ of the yield from decreasing product (actual $\$ 21,000 \mathrm{x}$ $0.6=\$ 12,600)$.

3. The abovementioned two items are contracted between management and a representative of employees at the kick-off meeting of Kaizen as a pre-arranged agreement on how to assess the Kaizen effects and how to distribute the increased profit between the management and workers.

\subsection{Advantages and Challenges of Kaizen}

This section explores the advantages and challenges of transferring Kaizen to developing countries, particularly in Africa. They are divided into inherent advantages and opportunities.

of a salary gap of almost double between the public and private sectors. The more excellent they are, the more readily they move to a private company when the conditions are met. As a result, the job turnover is as high as $15 \%$ in some countries in a year ("Kaizen Knowledge-Sharing Seminar" sponsored by JICA, First Seminar in Ethiopia in 2016 and Second Seminar in Kenya in 2017). 


\subsubsection{Inherent Advantages of Kaizen Technologies}

For the implementation of Kaizen, such methodologies and tools as the 5S, 7 QC tools, and QC story are available as easy-to-learn and easy-touse kits which are of great value for problem-solving. There are also many practical guidebooks on how to apply these methodologies and tools. For example, a guidebook on the 7 QC tools explains not only how to use a control chart, cause and effect diagram, check sheet, histogram, stratification, and scatter diagram but also which seven tools should be used in each step of a QC story.

The $5 \mathrm{~S}$ is a Kaizen methodology which is often used at the beginning of Kaizen because it is considered easy-to-start. The $5 \mathrm{~S}$ can be described as a simple procedure. However, when we understand that the proper implementation of the simple $5 \mathrm{~S}$ has pervasive effects on improved quality and productivity, ${ }^{11}$ surfacing of $M u d a$, vitalization of the workplace, and fostering of people's Kaizen mind, we understand that the $5 \mathrm{~S}$ is a technology with an unexpectedly long reach. The next common step is to eliminate Muda. The concept of Muda is both broad and deep.

Many Kaizen technologies do not demand a large fund. In general, the borrowing rate of interest is high in developing countries, and it is not unusual for private banks to charge an annual interest rate of $20 \%$. Although the interest rate charged by public financial institutions is lower than that, the available public funds for lending are usually too limited to meet the entire funding demand of companies for loans. For SMEs, the borrowing procedure is often complicated and time-consuming even before the question of the interest rate coming into play, making it extremely difficult for them to access both private and public financial institutions. The need to increase investment or working capital for the purpose of increasing the production capacity must be met by funds in hand or by borrowing from relatives and friends. This means that SMEs often must pass over immediate business opportunities because of funding constraints. Kaizen, however, usually does not require large funding as it seeks rational ways of thinking rather than money. Many companies

\footnotetext{
${ }^{11}$ In the case of SMEs, productivity often increases by $10-30 \%$ with positive effects on quality as well.
} 
start Kaizen in appreciation of this fact. At those factories where Kaizen is thoroughly implemented, old machinery, which has passed its depreciation period, and machinery remodelled to have a higher function than the processing capacity stated in the catalogue are in operation. These are examples of reducing the need for investment by Kaizen to implement appropriate TPM and to establish and observe the standard work.

\subsubsection{Opportunities for Kaizen Transfer}

As private initiatives, Japanese companies planning to outsource their production to an East Asian country firstly transfer their production technologies, including Japanese-style Kaizen technologies, to a local outsourcing subcontractor. This is followed by direct investment to start production at a factory of its local subsidiary or joint-venture company. Local workers at this factory learn Japanese-style production methods and Kaizen technologies through QC circle activities, OJT, and sometimes training in Japan. Some of these workers may become owners of their own businesses and implement previously learned Kaizen ideas and methods. The transfer of Kaizen technologies often occurs when a Japanese subsidiary outsources production of parts to a local factory. In addition, as described in Chap. 2, there is a long history of assistance for Kaizen in developing countries by JICA, an international cooperation agency of Japan.

Kaizen at manufacturing sites has been an important element leading to high economic growth in Japan. Needless to say, it is important to harmonize product development, marketing, business strategy, other innovations, and investment with various policies, including fiscal, foreign exchange, labor, and education policies. When other conditions are harmonized with economic growth in this manner, Kaizen can be a powerful leading force for economic growth. The relationship between Kaizen and the economy is not solely a causal relationship as the reverse causality of economic growth stimulating Kaizen is also possible. Companies that introduce Kaizen tend to adopt an assertive business stance, achieving significant growth of their business performance. Kaizen is acutely needed by conservative companies whose business performance is declining. 
However, the reality tends to be the opposite as these companies tend to be reluctant to introduce Kaizen. To summarize, there is a two-way causation between Kaizen and economic growth: while the dissemination and expansion of Kaizen leads to economic growth, economic growth leads to the dissemination and expansion of Kaizen. In other words, Kaizen and economic growth proceed in tandem.

\subsubsection{Challenges of Kaizen Transfer}

How to develop capable organization as a promoter of Kaizen is a subject issue for examination when Kaizen is due for further expansion. Business consulting is an independent professional advisory service aimed at assisting a business owner and his/her organization to achieve the purpose and targets of the organization by means of solving problems of business management, taking opportunities to widen the knowledge possessed by the organization, and implementing any necessary reforms. ${ }^{12}$ However, in many cases, consultation service for Kaizen promotion to a specific company is implemented in a limited way for reasons of insufficient quality and quantity of consultants in developing countries. Therefore, the development of capable consulting organizations that can respond to wide range of demand is a critical challenge. These organizations should be structured and developed based on the breadth of the anticipated activities and number of consultants, as described below.

Four perspectives must be taken into consideration when determining the desirable form of a consulting organization. The first perspective is to structure an organization based on the type of business as a target. Manufacturing, construction, and services are examples of business types. Manufacturing can be further classified into textiles, garments, agricultural product processing, woodworking, metals, machinery, chemicals, and so on. The second perspective is based on the purpose of technology used for Kaizen. To be more precise, the consulting service is classified based on the expertise regarding quality, productivity, or other target areas of Kaizen. The third perspective classifies the consulting service

${ }^{12}$ The definition given by Kubr $(2005$, p. 12) is quoted here with some modifications. 
based on the size of the client company or organization. What the author's consulting experience in Japan and the survey on consulting demands in Turkey suggest is that the smaller the size (business) of the client, the stronger the demand for a town-doctor type of consultant capable of offering a wide range of advice and assistance. In large companies, there is instead some need for consultants who can act as advisors to the top management. The fourth perspective relates to the idea of establishing a consulting organization as a fixed or flexible organization in response to client needs.

The priority among these four perspectives for the establishment of an actual consulting organization depends on the type of Kaizen service to be provided (5S, elimination of $M u d a$, etc. with training, diagnosis, guidance, follow-up, etc.) and the number of consultants involved. There are four practically viable forms of consulting organization, as will be explained next (see Table 3.3).

Table 3.3 Forms of consulting organization

\begin{tabular}{|c|c|c|c|c|}
\hline \multicolumn{2}{|r|}{ Type of organization } & \multirow{2}{*}{$\begin{array}{c}\text { Target company } \\
\text { Micro and small } \\
\text { (enterprise) }\end{array}$} & \multirow{2}{*}{$\begin{array}{l}\text { Services/tools to } \\
\text { be provided } \\
5 \mathrm{~S}\end{array}$} & \multirow{2}{*}{$\begin{array}{l}\text { Number of staft } \\
\text { (consultants) } \\
\text { Several - ten }\end{array}$} \\
\hline a & Start-up & & & \\
\hline$b$ & $\begin{array}{l}\text { Business type-specific } \\
\text { (developed from } \\
\text { research institute) }\end{array}$ & Medium size & $\mathrm{QC}, \mathrm{IE}, \mathrm{PM}(+5 \mathrm{~S})$ & $\begin{array}{l}50 \text { or more } \\
\text { (in-house } \\
\text { consultants) }\end{array}$ \\
\hline C & Specialty-based & $\begin{array}{l}\text { Large } \\
\text { (company) }\end{array}$ & $\begin{array}{l}\text { TQM, TPS, TPM } \\
(+5 S+Q C / I E / P M)\end{array}$ & $\begin{array}{l}100 \text { or more } \\
\text { (in-house } \\
\text { consultants) }\end{array}$ \\
\hline d & $\begin{array}{l}\text { Flexible (business } \\
\text { type-specific and } \\
\text { specialty-based) }\end{array}$ & $\begin{array}{l}\text { Medium and } \\
\text { large size }\end{array}$ & $\begin{array}{r}(\mathrm{TQM} / \mathrm{TPS} / \mathrm{TPM}+ \\
5 \mathrm{~S}+\mathrm{Q} \text { C/IE/PM) }\end{array}$ & 50 or more \\
\hline
\end{tabular}

Source: Created by the author

The specialty-based organization has a system to mobilize highly skilled consultants within the organizations (start-up, business type-specific, and flexible) to form a specialist department. Therefore, specialty-based organization can coexist with other types of organizations

The flexible organization can exist based on the business type-specific or specialty-based organization, which can form project teams in response to needs of clients. The members of the team are selected from staff consultants 
- Start-up type organization

This is a form of consulting organization brought in soon after the commencement of services for Kaizen. The targets for consultation are micro and small enterprises and the tool used for Kaizen is the $5 \mathrm{~S}$ in most cases. The number of consultants involved varies from several up to ten, and the form of organization reflects neither the type of business nor the specialist field, such as quality or productivity.

- Business type-specific organization

When the parent body of the organization assisting Kaizen is a research institute for industrial technologies, the form of consulting organization with 50 or more in-house consultants tends to have vertically divided consulting departments following the structure of the parent body designed to correspond to specific business types. The targets for assistance include medium-sized companies and QC, IE, and PM (preventive maintenance) are increasingly used as tools for Kaizen.

- Specialty-based organization

When the targets for services include large companies, more advanced Kaizen services such as TQM, TPS, or TPM are required. Apart from a consulting department offering basic Kaizen technologies, this type of organization has developed specialist departments with consultants having specialist knowledge of quality, productivity, cost, and so on. At this stage, the number of in-house consultants is likely to exceed 100 .

- Flexible organization

Although both the business type-specific organization and specialtybased organization have their own advantages, they also have major disadvantages. The biggest disadvantage is their inability to respond quickly to clients' diverse needs for Kaizen services. For example, assume that company A, a client garment manufacturer, hopes to receive comprehensive assistance for Kaizen and that the introduction of advanced Kaizen technologies is required for a rapid increase in the company's productivity. Nevertheless, the maintenance of standards as a central tenet is sufficient as far as the quality aspect is concerned. In this case, it may be necessary to form a Kaizen project team for company A consisting of four consultants, that is, a consultant familiar with the garment industry, a consultant with rich experience in the sophisticated improvement of productivity, and two 
basic level consultants, in order to maintain the quality standards while rapidly increasing productivity. This kind of response becomes feasible when an organization has 50 or more consultants.

In a situation in which a public organization that supports Kaizen is active in rural areas in addition to the metropolitan area, the town-doctor type consultants who can cover broad issues are to be assigned in its rural offices. In a head office of the organization, in addition to town-doctor type consultants for basic Kaizen activities, a consultant unit that employs experts on specific industry or Kaizen methodologies may be established in order to deal with advanced level Kaizen needs. In the consulting business field, while there are general consulting firms covering all types of business and specialist fields, there are also consulting firms specializing in specific types of businesses, such as finance and tourism, where viable consulting is only possible with in-depth knowledge of the industry concerned. There are also consulting firms specializing in specific functions, such as production control, marketing, human resources development, and so on. There are also examples of a single consulting firm having internal structures to provide services specializing in certain types of businesses or functions. The general practice is to arrange a flexible project team to cater to the particular needs of individual clients.

\subsection{Concluding Remarks}

Kaizen refers to a continuous activity to fill the gap between the current state and the ideal state. Japanese people who have a strong sense of mottainai or Muda imported many management technologies from the US to reduce Muda, that is, to proceed with Kaizen. These imported technologies were transformed to Japanese Kaizen technologies incorporating such small group activities as QC circle activities to make management technologies more effective. TPS, of which Japan is very proud, is quite different, in that its idea is directly opposite to Ford's production system in a number of aspects. There is no question that it has had a significant impact on the idea of Kaizen. 
The 5S, 7 QC tools, and QC story are basic Kaizen tools. Meanwhile, TQM, TPS, and TPM are core Kaizen technologies, not unitary technologies but systems combining a number of technologies. Broadly defined, Kaizen includes both Kaizen using inherent technologies and Kaizen using management technologies, but narrowly defined Kaizen means Kaizen using management technologies alone. However, Kaizen for quality or for the preventive maintenance of machinery is difficult to proceed with solely using management technologies as substantial progress cannot be made without knowledge of inherent technologies. Because of this, it is desirable for a consultant team to include a consultant with detailed knowledge of inherent technologies.

Kaizen has four general features: (1) cost reduction through the rigorous elimination of $M u d a$, (2) participation of front-line workers in Kaizen and enhancement of their morale and capabilities, (3) application of Kaizen in correspondence with the level of the company, and (4) prioritization of the rational use of available resources over innovation requiring sizable investment.

There are eight guidelines of Kaizen implementation: (1) importance of actual implementation, (2) on-the-spot observation rather than deskbound discussions, (3) consumer orientation and the principle of quality first, (4) focusing on the bottleneck, (5) strong commitment by the owner, (6) Kaizen as a process of human resources development, (7) labor-saving coupled with the promotion of excellent employees, and (8) appropriate distribution of Kaizen results for motivation.

There appear to be various reasons for the acceptance of Kaizen by many countries: (1) availability of easy-to-start Kaizen menus corresponding to different control levels, (2) availability of easy-to-use Kaizen technologies, (3) no need for large funding, (4) transfer of Kaizen technologies by Japanese companies, (5) dissemination of Kaizen through Japan's Official Development Assistance (ODA), and (6) tandem progress of economic growth and Kaizen. For further effective dissemination of Kaizen at an advanced level, the role of a consulting organization is crucial.

We believe that almost all of these reasons are applicable to African countries. The implication seems to be that in all likelihood, a large number of enterprises in Africa will take off by introducing Kaizen with a clear understanding of its value in practice. 


\section{References}

Asahi Shinbun. (2013). Toyota Shin Genba Shugi Keiei (Toyota New Genbaism Management). Asahi Shinbunsha.

Fujita, A. (1978). IE no Kiso (Fundamental of IE). Tokyo: Kenpaku-sha.

Hosoya, K. (1984). QC teki Monono Mikata, Kangaekata (Point of View and Thinking in Perspective of Quality Control). Tokyo: JUSE Press.

Ichikawa, S. (1995). Gakushu to Kyoiku no Shinrigaku (Psychology of Learning Education). Tokyo: Iwanami-shoten.

Ishikawa, K. (1989). Hinshitsu Kanri Nyumon A (Introduction to Quality Control A). Tokyo: JUSE Press.

Japan Management Association. (1980). Toyota no Genba Kanri (Field-work Management in Toyota). Tokyo: JMA Management Center.

JIS Q 9024. (2003). Keizokuteki Kaizen (Continuous Improvement). Tokyo: Japanese Industrial Standards.

Kubr, M. (2005). Management Consulting: A guide to the profession (4th ed.). Geneva: International Labour Organization.

Matsushita, K. (2006). Hito wo Ikasu Keiei (Management to Vitalize Human Resource). Tokyo: PHP.

Monden, Y. (1985). Toyota Sisutemu (Toyota System). Tokyo: Kodan-sha.

Nitta, M. (1999). Kadai Tasseigata QC Story (QC Story for Task Achievement). Tokyo: JUSE Press.

Ohno, T. (1978). Toyota Seisan Hoshiki (Toyota Production System). Tokyo: Diamond-sha.

QC Circle Headquarters (Ed.). (1980). Fundamentals of QC Circles. Tokyo: JUSE Press.

Shingo, S. (1980). Toyota Seisan Hoshiki no IE teki Kosatsu (Consideration from IE on Toyota Production System). Tokyo: Nikkan Kogyo Shinbun-sha.

Suzuki, T. (1992). Shin TPM Program: Kako, Kumitate (New TPM Deployment Program for Processing and Assembling). Tokyo: Japan Institute of Plant Maintenance.

Wada, K. (2009). Monodukuri no Guwa (Mythology of Manufacturing). Nagoya: The University of Nagoya Press. 
Open Access This chapter is licensed under the terms of the Creative Commons Attribution 4.0 International License (http://creativecommons.org/licenses/ by/4.0/), which permits use, sharing, adaptation, distribution and reproduction in any medium or format, as long as you give appropriate credit to the original author(s) and the source, provide a link to the Creative Commons license and indicate if changes were made.

The images or other third party material in this chapter are included in the chapter's Creative Commons license, unless indicated otherwise in a credit line to the material. If material is not included in the chapter's Creative Commons license and your intended use is not permitted by statutory regulation or exceeds the permitted use, you will need to obtain permission directly from the copyright holder.

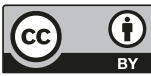

